\title{
FICCIONES DEL ACCIDENTE, ACCIDENTES DE LA FICCIÓN: TRAGEDIAS DE LA TECNOLOGÍA EN LA NARRATIVA HISPANOAMERICANA DE (POS)VANGUARDIA ${ }^{1}$
}

Fictions of the accident, accidents of fiction: tragedies of technology in Latin American (post) vanguard narrative

Eduardo Aguayo Rodríguez*

Resumen

El presente estudio tiene como objetivo describir el diálogo que la narrativa hispanoamericana de (pos)vanguardia sostuvo con la figura del accidente durante el siglo XX, a partir de un esquema de análisis que examina la asimilación de este fenómeno sociocultural en el plano del contenido, de la forma y de la recepción literarias. Para ello, establecemos un modelo de lectura basándose en las observaciones planteadas por Macedonio Fernández en su Museo de la Novela de la Eterna (1982), y analizamos desde este marco de referencia la figuración estético-política del accidente en una muestra ilustrativa de relatos.

Palabras clave: Accidente, Ficción literaria, Macedonio Fernández, Tragedia, Tecnología.

Abstract

This article describes the dialogue between Latin American (post)vanguard narrative and the figure of the accident during the twentieth century. We propose a model of analysis that examines the assimilation of this socio-cultural phenomenon in terms of literary structure, reception and content. We propose a reading model based on the insightful contributions of Macedonio Fernandez's Museo de la Novela de la Eterna, and analyze the political-aesthetical figuration of the accident in a corpus of exemplary texts.

Key words: Accident, Literary fiction, Macedonio Fernández, Tragedy, Technology.

\section{INTRODUCCIÓN}

En un trabajo anterior examinamos algunos antecedentes teóricos que nos permitieron definir al 'accidente tecnológico' desde una lectura cultural, explorando sus posibilidades de significación en el contexto de la modernidad tardía (Aguayo, 2011). Desde esta lectura entendimos que el accidente, en tanto signo, puede

\footnotetext{
${ }^{1}$ Este artículo presenta el análisis y los resultados obtenidos en el marco de la tesis de Doctorado en Literatura Latinoamericana de la Universidad de Concepción "La tradición del accidente en la narrativa latinoamericana contemporánea: el caso del automóvil en "Autopista del Sur", La guaracha del Macho Camacho y Los detectives salvajes, financiada por la Comisión Nacional de Investigación Científica y Tecnológica, CONICYT.
} 
funcionar como cifra de la incertidumbre radical sobre la que se despliega el orden occidental (pos)moderno; sobre este último aspecto, vimos cómo distintos autores coincidieron en leer al accidente y sus signos como la imagen cifrada de una sociedad paradójicamente controlada y ordenada por la racionalidad científica y tecnológica, sobre todo a partir de la segunda mitad del siglo XX (Paz 1991; Baudrillard, 1993; Virilio, 1997). Lo anterior nos permitió afirmar la pertinencia de "leer" la presencia muda de los objetos tecnológicos de la modernidad a partir del relato de sus anomalías, analizando algunas escenas y relatos claves que alimentan una "cultura de la casualidad" (Puskar, 2012:1) fundada en las tragedias y los milagros del automatismo descontrolado. Sobre este interés vuelve el siguiente artículo, examinando el caso que nos ofrece la ficción del accidente en la narrativa hispanoamericana de (pos)vanguardia. ${ }^{2}$

Tal como en la esfera social la masificación de la tecnología trajo consigo la multiplicación del accidente, conforme la máquina es incorporada al repertorio imaginario del cuento y la novela se constata la misma proliferación, constituyéndose, a nuestro juicio, un "discurso trágico" sobre la técnica ${ }^{3}$ que puede ser rastreado en distintas tradiciones literarias. Baste citar como ejemplo las distintas "colisiones" metafóricas y literales que ocurren entre humanos y máquinas en la narrativa inglesa desde mediados del siglo XIX estudiadas por Daly (2004); la proliferación imaginaria del Titanic y su hundimiento en la literatura y las artes plásticas alemanas de mediados del siglo XX, analizada desde una perspectiva fundamentalmente ecocrítica por Goodboy (2007), o el uso político de los eventos casuales como símbolo de libertad frente a la causalidad absoluta de los regímenes socialistas por parte de algunos narradores en el periodo de la guerra fría, tal como ha sido argumentado por Belletto (2012). En el caso hispanoamericano, podemos afirmar que la imagen del accidente ha sido asimilada por la ficción ya desde las vanguardias, para figurar una representación del mundo y para definir una cierta práctica estética y política, una forma específica de 'producción' y 'recepción' literarias, como la misma reflexión metaliteraria de algunos autores parece indicar.

Teniendo en consideración estos antecedentes, nos interesa analizar ahora algunas de las formas en que la ficción provoca y sufre accidentes en el ámbito de la narrativa hispanoamericana del siglo XX. Para ello, definiremos un breve esquema de

\footnotetext{
${ }^{2}$ Empleamos el término “(pos)vanguardia” tal como ha sido utilizado por Rodríguez y Rodríguez (2008) para referirse a una línea de autores caracterizados por asumir en su escritura la crisis de las perspectivas totalizantes sobre la realidad y la ficción a lo largo del siglo XX. Optamos por agrupar a los autores que estudiamos - Macedonio Fernández, Julio Cortázar, Luis Rafael Sánchez, Roberto Bolaño - bajo este término por cuanto nos permite dar cuenta de un cierto proceso histórico iniciado con las vanguardias y continuado durante toda la segunda mitad del siglo XX por un grupo de escritores autores vinculados por este gesto ético y estético.

${ }^{3}$ Recordaremos solamente, en este punto, que la misma noción de peripecia, "giro súbito e inesperado [...] que produce sorpresa" (Beristain, 1995:390) y que modifica sustancialmente el desarrollo de las acciones es una suerte de "accidente" en el orden previsible del relato.
} 


\section{Eduardo Aguayo}

análisis a partir de ciertas claves sugeridas por la lectura de Museo de la Novela de la Eterna de Macedonio Fernández, y aplicaremos este modelo sobre una muestra ilustrativa de tres textos relacionados entre sí por la presencia de un objeto tecnológico particular: el automóvil.

\section{LA POÉTICA DEL ACCIDENTE EN MUSEO DE LA NOVELA DE LA ETERNA: UN ESQUEMA DE LECTURA}

No es esta la instancia adecuada para intentar el abordaje en profundidad de una obra tan compleja como lo es el texto de Fernández; al contrario, es necesario partir reconociendo que la lectura que proponemos de la novela de Fernández es estrictamente utilitaria y se subordina al tema que orienta este estudio. La selección de esta obra literaria como referencia teórica no es arbitraria. Justificamos tal decisión apelando al carácter metaliterario de la obra en cuestión, verdadera "teoría de la novela" en palabras de Piglia (2000:7), y sobre todo a la presencia explícita y variada de los accidentes a lo largo del "relato", presencia a partir de la cual Macedonio Fernández construye una poética y una política de la incertidumbre.

Un punto de acceso lo encontramos en un pasaje breve pero significativo del texto, donde el narrador define la novela como una obra que, mientras presenta al lector el desarrollo de los eventos, "es arrollada por otros [acontecimientos], contiene accidentes y sufre accidentes" (201). Como vemos, los accidentes pueden ofrecer un sustrato temático para la ficción pero también pueden ser considerados como 'efectos' que se ejercen sobre y desde la ficción. El símil al que recurre el narrador para ilustrar esta idea se apoya, como cabría esperar, en una imagen de la modernidad tecnológica: al igual que un tranvía, que va repartiendo "choques y sustos" (201) mientras se desplaza por la pista, pero que al mismo tiempo ilustra a sus ocupantes mediante avisos sobre las precauciones y los peligros que deberán considerar cuando vuelvan a ser peatones, la novela de Macedonio se autoseñala como una máquina "portadora" a la vez que "productora" de eventos inesperados.

¿Quiénes son los que sufren estos accidentes de la novela? La respuesta la encontramos en otro de los prólogos que componen la novela, significativamente titulado "Como ha sido posible, al fin, la novela perfecta", que amplía el esquema básico anterior; en este caso, el narrador refiere la historia de Juan Pasamontes, arquetipo narrativo que encarnaría con sus accidentes la "esencia" misma de todo argumento: el ir y venir de los acontecimientos, el cambio de fortuna que "sirve en la novela para principiarla y en la vida de Pasamontes para suspenderla, en el lector para mantenerlo suspenso de preocupación y en el relato para marchar" (219); en este caso, el accidente como un metafórico motor narrativo pone en acción al lenguaje literario, al punto de entenderlo como su "principio", es decir, como un comienzo pero también como una "propiedad" fundante de todo relato; más importante aún, la cita identifica una dirección específica hacia la cual los accidentes de la ficción movilizan al relato: el lector. En efecto, la novela enfatiza que todo relato que aspire al 
éxito debería "empezar su narrativa por un choque o una buena frenada [puesto que] el público se junta al punto en tal número que ya quisieran algunos libros tener el de una frenada común" (203-204). Pero la relación entre accidente y lector no se agota en esta especie de truco publicitario, ${ }^{4}$ como veremos.

Integremos, antes de continuar, los elementos examinados en una sola proposición: para el modelo de 'Museo', un relato se inaugura 'sufriendo' accidentes, conteniéndolos y experimentándolos, con el fin último de 'impactar' a su lector. La novela de Fernández es en sí misma una estructura accidentada: es un texto compuesto sólo de prólogos que suspenden indefinidamente el comienzo de la lectura o, para ponerlo en palabras de su narrador, "un libro tan zanjeado que no hubo recurso sino leerlo seguido para mantener desunida la lectura, pues la obra salteaba antes" (200). La ficción se constituye, de esta forma, forma irregular, elíptica o discontinua, un "lenguaje fracturado" (Piglia 2001:11) por el cual circulan las voces del mundo, como sucede con La guaracha del macho Camacho (1994), de Luis Rafael Sánchez; Los detectives salvajes (1998) de Roberto Bolaño, o Rayuela e incluso Continuidad de los parques, de Julio Cortázar. Pero la posibilidad de un "accidente de lector" (Fernández, 1982:247) no se limita al desafío que plantea la lectura de un lenguaje fracturado en la forma, sino que también abarca los riesgos "existenciales" que amenazan con fracturar el orden o el mundo del lector.

En efecto, hay textos que buscan afectar el horizonte de la lectura con el carácter irregular o accidentado del mundo ficticio en el que se nos instala. La figura del accidente permite imaginar esta 'afectiva', en la medida en que involucrarse en la lectura de un texto diseñado para sufrir y hacer sufrir accidentes o que funciona como una máquina colisionante supone abrirse a una experiencia potencialmente incontrolable. Son libros peligrosos en la medida en que en ellos siempre será posible pasar "de un lleno de novela a un vacío atencional" (Fernández 1982 248) lo suficientemente radical como para modificar el horizonte imaginario del lector y con esto la percepción que tiene de sí mismo y del mundo. Ningún lector -incluyendo al crítico- está a salvo de perderse en la lectura o de volverse loco o de pasar por lo menos por una "violenta acomodación mental" para entrar en esta máquina "de intensidad única" (Ibid. 248) como resulta la novela de accidentes. Lectura

\footnotetext{
${ }^{4}$ Sabemos que Baudrillard (1993;2009) ha elaborado una explicación consistente acerca de los factores sicológicos y sociales que influyen en el consumo simbólico masivo de la muerte accidental mediatizada por los siniestros tecnológicos en las sociedades occidentales durante gran parte del siglo XX, fenómeno de seducción propio de una sensibilidad moderna que parece replicarse en el fragmento; sin embargo, parece improbable que Fernández propusiese alcanzar la misma masividad o fuerza de atracción, el mismo potencial de consumo que tienen los hechos narrados por la crónica roja a través de una especie de 'morbo-ficción', y más improbable aún que Fernández apuntase a ese mismo tipo de masividad instantánea con su novela, especialmente si se considera que la escritura de su Museo, ejemplo de novela esquiva en cuanto a público, fue una suma de comienzos e interrupciones que se extendió desde 1904 hasta prácticamente la misma fecha de su muerte, en 1952, y que fue finalmente publicada sólo una década y media después, en 1967.
} 
catastrófica que inaugura un cierto discurso crítico y contingente: recordemos, a modo de ejemplo, la propuesta de Carlos Fuentes, cuando señala como uno de los objetivos de su programa escritural "reinventar la historia, arrancarla de la épica y transformarla en personalidad, humor, lenguaje, mito: salvar a los latinoamericanos de la abstracción e instalarlos en el reino humano del accidente, la variedad, la impureza" (1997:190). Transformar la historia en accidente por medio de la ficción significaría ante todo contrarrestar la ilusión de un relato unitario y definitivo que explique el (des)orden del mundo, abriendo un flanco de incertidumbre a través del cual sea posible afectar la realidad histórica del lector y su lectura. En este sentido, 'accidentar la lectura', leer el accidente' puede homologarse a descifrar un mensaje "bajo peligro de muerte, una hermenéutica privada y paranoica" (Piglia, 2001:184) que eventualmente nos permita reconocer, como lectores, la clave trágica del mundo (Zambrano 1996).

Vistos estos antecedentes, examinemos ahora algunos relatos que ilustran distintas modalidades de "accidentes de ficción" en la narrativa hispanoamericana durante la segunda mitad del siglo XX. Nos centraremos en tres relatos fundamentales: "Autopista del sur" (2005) de Julio Cortázar, La guaracha del macho Camacho (1997) de Luis Rafael Sánchez, y Los detectives salvajes (1998) de Roberto Bolaño, textos de "alto impacto" editorial y sin duda notables en cuanto a su complejidad formal.

ACCIDENTES DE FICCIÓN, FICCIONES DEL ACCIDENTE EN HISPANOAMÉRICA: DE CORTÁZAR ABOLAÑO

"Los automovilistas acalorados parecen no tener historia. Como realidad, un embotellamiento automovilístico impresiona pero no dice gran cosa" (Cortázar, 2005:57). El epígrafe con el que se inicia “Autopista del sur" propone los ejes sobre los cuales se construye el relato de Cortázar: historia, realidad y sobre todo 'sentido'. Como cabría esperar, el tratamiento ficcional de este accidente se asume desde una estética fantástica, lo que en la práctica implica, para Cortázar, una opción política. Sabemos que la tarea de "cruzar ciertos límites" ordenadores para permitir "la erupción de lo otro" en la ficción es asumida por Cortázar como una de las tantas formas en que el escritor opera con la incertidumbre del mundo para "salvarnos de ese robot obediente en el que tantos tecnócratas quisieran vernos convertidos y que nosotros no aceptaremos jamás" (1994:111). En este sentido, los accidentes generalmente contenidos en su ficción aparecen vinculados con la modificación de la "normalidad" cotidiana y sus parámetros, ${ }^{5}$ gesto con el cual pone en contacto realidades que de otra forma permanecerían incomunicadas.

\footnotetext{
${ }^{5} \mathrm{Al}$ respecto, señalemos la fractura del principio de la identidad, que dice que uno no puede ser al mismo tiempo distinto de uno, es decir, otro, en La isla al mediodía, o la del principio de evolución histórica, donde el presente es la superación del pasado y la antesala del futuro en La noche boca arriba.
} 
Como lo ejemplifica el mismo Cortázar en Rayuela (1996).

Los albañiles, los estudiantes, el clochard, la vendedora de lotería, cada grupo, cada uno en su caja de vidrio, pero que un viejo cayera bajo un auto y de inmediato habría una carrera general hacia el lugar del accidente, un vehemente cambio de impresiones, de críticas, disparidades y coincidencias hasta que empezara a llover otra vez y los albañiles se volvieran al mostrador, los estudiantes a su mesa, $\operatorname{los} \mathrm{X}$ a $\operatorname{los} \mathrm{X}, \operatorname{los} \mathrm{Z}$ a $\operatorname{los} \mathrm{Z}(92)$.

Tanto Cortázar como sus comentadores han coincidido en ofrecer una lectura de "Autopista del sur" como una "visión utópica de 'alternativa al mundo contemporáneo' "(Matas, 1973:148). Liberados del sometimiento que impone el tiempo cronológico, inorgánico, de la máquina y de "todo lo que esclaviza al hombre, física y moralmente" (Filler, 1970:90) e igualados por la condición excepcional en la que se encuentran, los automovilistas bajan de sus máquinas, escapan al aislamiento privado e individual, se "encuentran" en medio de la carretera y superan, en mayor o menor medida, la deshumanización a la que se ven sometidos; simbólicamente, las puertas abiertas de los automóviles implican la aceptación del libre tránsito de la vida por parte de estos personajes, que intercambian agua, alimentos, ropas e incluso libros, pero que también intercambian opiniones, historias, confidencias, hasta finalmente terminar por "intercambiarse" ellos mismos de automóvil en automóvil, en una "convivencia comunitaria utópica" (De Mora, 1982:48) basada en "la libertad de elección, la solidaridad, los ritmos lentos" (Varanini, 2000:307) "la amistad y hasta el amor" (Rein, 1967:54). No participar de este intercambio, parece decirnos el relato, equivale a rechazar la vida (Antonucci, 1985). El fracaso de esta utopía y el ingreso de la tragedia a este pequeño nuevo mundo vendría señalado por la dispersión con la que finaliza el relato, en palabras de Cortázar una "dispersión fatal de gentes que finalmente habían terminado por encontrarse y formar una pequeña sociedad, un pequeño grupo" (Picon, 1978:81), pero que no pueden impedir el retorno a un "orden inhumano" (Paley De Francescato, 1975:130).

Pensamos que una lectura más atenta a los detalles que configuran el accidente de la ficción puede revelar algunos aspectos menos evidentes sobre esta comunidad utópica y el orden que la rige. Centrémonos, para ello, en la voz de Taunus, personaje que, a juicio del ingeniero desde el cual se focaliza el relato, "evidentemente sabía mandar" (66). El texto señala que la comunidad es "el grupo de Taunus", un cuerpo organizado en torno a la autoridad del caudillo que garantiza unidad y permanencia: no cumplir con su ley, no obedecer sus instrucciones, no seguir sus gritos, incluso no escuchar sus chistes, implica un potencial de incertidumbre que se concibe, para la estructura de este grupo, como intolerable. De ahí que, cuando lo accidental emerja, como sucede con el incendio fortuito provocado por "alguien que había querido hervir clandestinamente unas legumbres" (Cortázar, 2005:69), la respuesta de Taunus consista en reafirmar, por la vía del temor, la "natural" necesidad de su orden: "Taunus bromeó 


\section{Eduardo Aguayo}

sobre lo sucedido mientras iba de auto en auto para ver cómo habían pasado todos la noche, pero a nadie se le escapó lo que quería decir" (69, énfasis mío).

Desde esta perspectiva, la utopía de la autopista sería la historia de una comunidad paralizada por la omnipresencia de la certidumbre; la naturalización de tal poder en la comunidad - repitamos que el ingeniero sentía "una confianza instintiva" en Taunus (66) - queda sin embargo cuestionada por los accidentes que, de manera ficcional, permean el mundo narrado. Pensemos, por ejemplo, en la incertidumbre que rodea las causas que originan la situación extraordinaria en la que se encuentran: algo muy grave debería haber sucedido para que el grupo permaneciera tantos meses detenido en plena carretera, pero los habitantes de esta comunidad, incluido Taunus, solo disponen de noticias probablemente falsas, "mitos", para dar sentido a la experiencia incomprensible en la que se hallan: no existe "el" accidente original respecto del cual se pueda formular una esperanza de solución para restablecer la continuidad, solo hay una acumulación incompleta de accidentes falaces, diseminados por una voz ajena al orden central que impone Taunus, precisamente la voz de los forasteros que llegan desde más allá de los límites del perplejo grupo, propagando historias por el solo placer de su difusión - "el extranjero saboreaba el éxito de sus novedades, los golpes de portezuelas cuando los pasajeros se precipitaban para comentar lo sucedido" (60) - y develando, sutilmente, el carácter ficticio de las voces que narran la realidad social del grupo. No hay causa razonable que explique su estado, solo proliferación de ficciones:

Se había sabido así del choque de un Floride contra un 2HP cerca de Corbeil, tres muertos y un niño herido, el doble choque de un Fiat 1500 contra un furgón Renault que había aplastado un Austin lleno de turistas ingleses, el vuelco de un autocar de Orly colmado de pasajeros procedentes del avión de Copenhague (60).

Este detalle permite conectar el texto de Cortázar con una lectura más afín a nuestro esquema: frente al simulacro de normalidad y certidumbre que el poder construye como estrategia de legitimación, los accidentes en la ficción evidencian el carácter no esencial, eventual, del orden que rige el mundo narrado, y al mismo tiempo establecen un espacio de libertad imaginaria para los habitantes de la comunidad, la posibilidad de formular un sentido distinto al establecido por la voz oficial que explica tal mundo. De este modo, la aceleración y dispersión con la que finaliza el relato — descrita como "un pesado pero incontenible movimiento migratorio que despertaba de un interminable sopor" (79) — más que una tragedia, nos parece la reafirmación de las posibilidades vitales frente al orden inercial de la certeza; es como si el relato subrayara que no importa lo estable o sólido que resulte la dominación — generalmente atroz - del hombre por el hombre, el inevitable devenir de lo vivo no puede transcurrir en otra dirección que no sea la de la indeterminación. 
Pero hemos dicho que los accidentes de la ficción asumen la forma de la tragedia. En este sentido, trágico resulta, para recuperar con esto la opinión de Cortázar, la separación forzosa de quienes habían logrado encontrarse, y que se desencadena en el relato no por la indeterminación, sino que precisamente por el exceso de certidumbre: "Taunus les ordenó a gritos que volvieran a sus coches" (79), señala el narrador. Y el ingeniero, obviamente, obedece. Ese sería el germen de la tragedia, por eso el 404 pierde a Dauphine, su "compañera de viaje": por ignorar el carácter inhumano de las certezas totales y del poder que las enuncia.

La figura del embotellamiento - que podríamos denominar como "el cronotopo del tapón": un tiempo de espera en un espacio colapsado- se replica en $L a$ guaracha del macho Camacho, esta vez con algunas notables variaciones. Destacamos, en primer lugar, que la espera no se encuentra circunscrita a la esfera privada del automóvil, sino que se actualiza en otros espacios del relato (Graciela en la sala de espera del psiquiatra, la China Hereje en el "Furnished studio", los pasajeros en la "guagua" o transporte colectivo); tampoco se desarrolla como un acontecimiento "fuera" del tiempo/espacio "normal" y "normado" - como ocurría con la espera en el cuento de Cortázar, situada en el ambiguo tiempo del fin de semana y en medio de una carretera interurbana-, sino que ocurre en el centro de este: en las calles de la capital nacional, en medio de la semana, a media tarde, "tarde de miércoles hoy, cinco pasado meridiano" (Sánchez, 1994:14). La (in)acción narrada se sitúa, de esta forma, en un marco de circunstancias políticamente contingente, que se cifra en el desperfecto, cotidiano ejemplo de una situación que no marcha, "porque se fue la luz, porque la luz se va todas las tardes, porque la tarde no funciona, porque el aire acondicionado no funciona, porque el país no funciona" (21).

Recordemos a este respecto que la novela de Sánchez, publicada por primera vez en 1976 no en el Puerto Rico natal de su autor; sino que en Argentina, fue tempranamente caracterizada como una obra de denuncia por parte de un sector de la crítica que vio en ella el ejemplo de una "nueva novela del Caribe" (Román, 1981:243) comprometida en clave irónica y transgresora con la contingencia histórica y política del problemático Estado Libre Asociado. El mismo Sánchez subraya la decisiva influencia de ciertos factores políticos, históricos y sociales en la definición de las poéticas, temáticas y circuitos de publicación y recepción de la literatura borriqueña desde mediados del siglo $\mathrm{XX}$, factores que tendrían su causa común en el estatus colonial de la isla (Sánchez, 1997); Puerto Rico, "colonia sucesiva de dos imperios e isla del Archipiélago de las Antillas" (Sánchez, 1994:13), no tiene cuerpo propio, no logra constituirse en ente autónomo: o es de otro o es uno más.

Siguiendo esta lectura, el embotellamiento de tránsito "muestra ágil el tapón de la capacidad criolla para el atolladero" (Sánchez, 1994:27) puede leerse claramente como una irónica imagen de la histórica situación política de la isla, sobre todo si seguimos los indicios que nos da su topografía: el tapón se "organiza" en un tramo que comienza en el "Puente de la Constitución" y termina en la "Avenida Roosevelt", 
cruzando la "Carretera Kennedy" y el "antiguo matadero"; la onomástica asociada a los puntos del trayecto sintetizan, de esta forma, el estancamiento histórico en el que se encuentra la colonia norteamericana, sin otra alternativa que la dominación o la muerte (Vaquero de Ramírez 1978). Es interesante que la imagen del embotellamiento automovilístico como expresión del estancamiento político y social de Puerto Rico pueda señalarse como una verdadera constante sobre la cual se funda una suerte de "literatura del tapón", especialmente a partir de la obra de Emilio Díaz Valcárcel y su novela El hombre que trabajó el lunes, de 1966. Al respecto, De la Fuente (2006) cree ver en estas congestiones vehiculares cierta "forma contemporánea e individual del insularismo" (2006:45), refiriéndose con esto al proceso de reducción espacial al que se ve sometido el puertorriqueño "moderno", conducido por un desarrollo histórico que lo desplaza desde el campo, abierto y comunitario, hacia el espacio escaso y privado de la casa, el automóvil y el motel. La utilización del término "insularismo" no es arbitraria, por cuanto remite a la obra Insularismos (1934), de Antonio Pedreira, donde se ensaya una interpretación histórica y cultural de Puerto Rico recurriendo sugerentemente a la imagen de un "navío sin rumbo" que simbolizaría la desorientación política, social y cultural del país caribeño tras la invasión sufrida por Estado Unidos en 1898. Este sería el momento inaugural del Puerto Rico moderno, cuando, en palabras de Pedreira, "una mano guerrera nos quebrantó el timón, quedando nuestra nave al garete" (2004:37). De ahí que Mercedes López-Baralt (2004) se refiera a los constantes embotellamientos vehiculares presentes en la ficción puertorriqueña ${ }^{6}$ como una reelaboración de esta imagen fundacional: Puerto Rico es una nación encallada, y la ficción haría presente este "accidente histórico" en el curso de estos relatos.

Esta suerte de certeza histórica permitiría contrastar, a nuestro juicio, la imagen de mundo propuesta por el relato de Cortázar con la sostenida por la novela de Sánchez (1994), cuyos accidentes ficcionales, fruto de la fantasía estomacal de los isleños, más que proponer una visión alternativa de mundo enmascaran el mal gobierno que rige sobre la isla encallado:

No es que la luz esté dañada ni cosa por el estilo ni que la crisis energética ni que con qué se come eso. Que es que un camión transportador de petróleo se tiró, se fue, se cayó, se viró contra un Volvo nuevecito manejado por una mujer en estado interesante: el feto se le anudó en la boca. Que es que una guagua escolar estropeó unos huelguistas. Que es que unos huelguistas estropearon una guagua escolar (95).

\footnotetext{
${ }^{6}$ López-Baralt cita como ejemplos, entre otros casos, el del Pontiac rodeado por las aguas del Río Loco en Vecindarios excéntricos (1998) de Rosario Ferré, así como el de los vehículos atrapados al final de Historia de un dios pequeño (2001) de Elidio La Torre Lagares.
} 
Esta especie de "grotesco social" que se funda en el imaginario accidental de la novela se codifica bajo un signo esencialmente negativo, lo que se evidencia en el único accidente "real" que se verifica en el relato y que adopta la forma de un crimen. Así, la aceleración del Ferrari, que duplica el desenlace de Autopista del sur, concluye no en un final abierto a la indeterminación sino que en un atropello, clausurando o limitando las posibilidades de lo imaginario. Se reemplaza, de esta forma, la 'incertidumbre' por la 'injusticia', ideológicamente situada en un alienado personaje de la burguesía dominante, el joven Benny, quien resulta incapaz de articular algo distinto a "Yo no tuve la culpa" (Sánchez, 1997:255); sin embargo, tal como lo hace notar Solotorevsky (2002), lo anterior no significa que el texto concluya trágicamente con este episodio, puesto que el posible impacto patético del hecho quedaría suspendido por la irrupción del humor negro y lo grotesco, rasgos que en efecto predominan durante todo el relato. ${ }^{7}$ Ejemplo de esto es el tratamiento irreverente que recibe el cuerpo despedazado de "El Nene", con sus ojos "estrellados por la cuneta como huevos mal fritos" (255) o la imprecación final del autor del atropello: "Me cago en la abuela de Dios" (255). Y si este patetismo ambiguo atenúa la posibilidad trágica de la novela, más lo hace la imposibilidad de ofrecer a la lectura un '(re)conocimiento' del mundo a partir de este episodio, salvo el conocimiento de las culpas: nada parece quebrar la ignorancia histórica en la que se encuentra Benny, como tampoco ocurre con los personajes de otro relato puertorriqueño contemporáneo al texto de Sánchez, Mercedes Benz 220 SL, de Rosario Ferré. ${ }^{8}$ En otras palabras, ambos accidentes funcionan como síntomas del desarreglo políticosocial que subyace a la nación caribeña, pero cifran una explicación para este desperfecto social en una sola causa "comprensible": la corrupción "natural" de la sociedad burguesa, capitalista e imperialista. De ahí que podamos afirmar que el único conocimiento que parece validado por ambos relatos puertorriqueños sea el de la asignación de las culpas - conocimiento afirmado en la imaginación del lector, puesto que aparece negada constantemente a la conciencia del personaje - y que lleva al castigo o en último término al dudoso desenfreno del guaracheo.

Finalmente, una versión distinta del mismo problema nos ofrece el caso de Los detectives salvajes, relato que además de ser la recreación ficcional de la vida del

\footnotetext{
${ }^{7}$ La autora denomina a esta característica textual inestabilidad patemática, ya que el afecto movilizado por el texto sobre su receptor nunca queda completamente definido como pathos, sino que más bien se mantiene fluctuante "entre un ethos humorístico y un ethos trágico" (Solotorevsky, 2002:41).

${ }^{8}$ Resulta muy significativo que el cuento de Ferré — narrado principalmente desde la voz de una madre que ha sido cómplice ignorante de la muerte de su hijo - repita una serie de elementos presentes en el relato de Sánchez. Observamos, por ejemplo, la vulgarización humorística del accidente: "el impacto sordo del tapalodo conectando de golpe en la carne compacta como cuando se tapa el tubo de la aspiradora con la palma de la mano fop" (1987:53); la figuración grotesca del cuerpo: "meciéndose en el suelo todo el tiempo con la cabeza una pulpa violácea encharcándole la falda" (54); la criminalización del accidente y la culpabilidad elidida: "cuando el hombre se nos tiró debajo de las ruedas del carro"(60), y sobre todo la cancelación completa de (re)conocimiento a partir del hecho: "yo con la boca abierta [...] sin poder entender todavía de dónde venía aquella cosa que seguía retorciéndose dentro del pecho" (62).
} 
poeta Mario Santiago, muerto por atropello a los 44 años, evoca escenas de una "cierta derrota generacional" (Bolaño, 2004:327); ${ }^{9}$ destaquemos que, a pesar de esto, Bolaño deja lugar para los matices: también podemos leer su novela como una agonía, como un juego o como la instantánea de una felicidad radical y efimera. No hay que olvidar que el nihilismo de Bolaño se confunde frecuentemente con sus posiciones vitalistas: "El mundo está vivo y nada vivo tiene remedio y esa es nuestra suerte", señalaría, según Jorge Herralde, uno de los epitafios apócrifos del escritor (2005:29). Si el apocalipsis y la aventura, el aniquilamiento final y el vértigo de lo porvenir son las dos tradiciones que alimentan, según Bolaño, la literatura hispanoamericana actual, bien podríamos considerar a Los detectives salvajes como una suma equilibrada de ambas, por lo que no debería resultarnos extraña la presencia de los accidentes en su desarrollo; sin embargo, los desastres tecnológicos explícitamente representados son más bien una excepción: no hay colapsos de tránsito ni proliferación de colisiones o atropellos, salvo el desgraciado fin de la joven Laura Damián, transformada en mito artístico, en premio literario y en presencia fantasmagórica tras morir arrollada por un coche; lo anterior no implica, como intentaremos demostrar, que la imagen del accidente no pueda ser "leída" de forma significativa en este texto, sobre todo si atendemos con detenimiento la evolución de un automóvil en especial: el Chevrolet Impala de la familia Font.

Recordemos que en la novela el automóvil es tomado "prestado" por los poetas/detectives Belano y Lima y por la pareja compuesta por Lupe y el joven García Madero en su fuga desde el DF hacia el desierto de Sonora. El "retorno" del Impala a su dueño original ocurrirá una década después de la fecha en que "finaliza" la última parte de la novela. Nos narra este encuentro el arquitecto Joaquín Font, quien acaba de regresar a su hogar tras una temporada de reclusión en el manicomio: mirando el tráfico tras la verja de hierro que separa la calle del jardín, el narrador ve cruzar su Impala, marcado con las huellas que ha dejado su paso por el tiempo, "con abolladuras en los guardabarros y en las puertas, con la pintura descascarada" (403); a pesar de la distancia física que los separa, el encuentro con esta máquina fantasma impacta al narrador, y la ficción registra las huellas de esta colisión: Font tiembla al punto de perder sus anteojos, deteriorándose, por lo tanto, la claridad de su enfoque.

\footnotetext{
${ }^{9}$ La crítica ha destacado las distintas formas que adopta la "poética del fracaso" en Bolaño: en un nivel particular, como "fracaso personal", varias obras principales en la producción del chileno suelen aparecer como registros que testimonian "la desaparición de su generación" (Spiller, 2009 153), tematizada, por ejemplo, en la continua presencia de acontecimientos históricos que retratan el fin de la utopía revolucionaria en la América Latina, como la masacre de los estudiantes en la plaza de Tlatelolco, en octubre de 1968, o el golpe militar chileno de 1973; a nivel más general, el fracaso expresa también la crisis terminal por la que atravesaría el paradigma humanista moderno y su forma política fundamental las democracias liberales - en un contexto social hasta cierto punto indefinible: "capitalismo tardío, globalización, posmodernidad" (Morales, 2008:55). En este sentido los textos de Bolaño no se unirían al coro que canta la gran elegía latinoamericana tras la muerte irreversible de sus revoluciones, sino que más bien irrumpen en este canon de voces concertadas con un sonido escéptico y discordante apropiado con lo que Ortega señala como su débil “estética de la indeterminación” (Ortega, 2009:54).
} 
La visión que sigue a este impacto activa la incertidumbre en la ficción, y surge el enigma trágico: ¿Quién conduce al Impala? La pregunta no solo expresa el deseo del narrador por devolver la certidumbre al mundo narrado, sino que también expresa el propio deseo de Font por ver tras el volante a su juventud, a su esperanza, a Cesárea Tinajero, abriéndose paso "desde el tiempo perdido para devolverme el automóvil que yo más había querido en mi vida" (403). Sabemos que el curso del relato toma otro camino: no es la personificación de la poesía ni de la revolución ni de la utopía ni ningún otro espectro de la modernidad quien conduce la máquina: al contrario, no hay nadie conduciendo al Impala fantasma.

El enigma que impone la visión del Impala prepara al relato para un (re)conocimiento trágico que emerge de otro "accidente" incorporado a la ficción, en este caso, el desmoronamiento metafísico que termina por confundir las marcas de identidad subjetiva del narrador con la objetividad del mundo narrado. El mismo Font señala que "la calle se había transformado en un rompecabezas de penumbra al que le faltaban varias piezas, y una de las piezas que faltaban, curiosamente, era yo mismo" (404). En esta suerte de mecanismo impreciso, incompleto, narrador y máquina, sujeto y objeto, coexisten reconciliados en la figura imposible de la paradoja: "Mi Impala había vuelto a mi mente. Yo había vuelto a mi mente" (404). No es nuestra intención ofrecer una interpretación a la proposición de Font, porque nos parece que su función narrativa precisamente consiste en "accidentar" la lectura, en impedir un ajuste regular y previsible de los sentidos propuestos por el relato. Sí quisiéramos señalar, para concluir con este análisis, que el desarreglo lógico por el que transita la narración da paso a un reconocimiento clave para la novela: "Supe entonces" señala Font— "con humildad, con perplejidad, [...] que estábamos gobernados por el azar y que en esa tormenta todos nos ahogaríamos" (404). Nos reencontramos así con la irremediable incertidumbre que ya aparecía sugerida en el cuento de Cortázar, y nos alejamos al mismo tiempo de la certidumbre ideológica que por momentos tiende a insinuarse en el texto de Sánchez: para Bolaño, en un orden que se sostiene paradójicamente sobre lo incierto, la opción que se propone desde la ficción no consiste en "reparar" un imposible error original ni asignar la "culpa" como solución al descontrol del mundo, sino que más bien llama a mantener, humilde y perplejamente, la "lucidez" de la experiencia - como expresa el narrador, "mantenerse a flote un poco más de tiempo" (404) - mientras se acerca el naufragio irreversible.

\section{CONCLUSIONES}

El análisis precedente nos ha permitido demostrar la validez de explorar diferentes significaciones de un fenómeno disruptivo, el accidente, en el contexto de los imaginarios tecnológicos de la literatura latinoamericana. Pudimos comprobar cómo cada texto analizado puso en funcionamiento "accidentes de ficción" particulares, de acuerdo con su propio horizonte retórico-ideológico. En el caso de 


\section{Eduardo Aguayo}

Cortázar el accidente respondió a los mecanismos de ficción propios de su prosa fantástica, expresando al mismo tiempo una posibilidad crítica contra la organización de la sociedad de control. En el caso de Sánchez, y distanciándose de Cortázar, lo corpóreo y lo grotesco se conjugaron para derivar una certidumbre ideológica a partir de lo incontrolable: el señalamiento de un culpable. Finalmente, en Bolaño la certeza en la incertidumbre intenta cancelar, por su mismo carácter abismal, la distancia crítica que asegura el lugar del sujeto en el mundo. Distintos intentos de dar forma y sentido, de imaginar y de conocer la abrumadora intensidad de la historia humana, "esa cosa tan pequeña y transitoria, tan reiteradamente aplastada por terremotos y guerras, tan cruelmente puesta a prueba por los incendios y naufragios y pestes y muertes de hijos y padres" (Sábato, 2006:131).

Pensamos que como dispositivo textual, el accidente de la ficción funciona como la manifestación de lo que no ha sido ni previsto ni predicho por la racionalidad instrumental moderna a través de una forma 'trágica', por lo menos en dos sentidos: porque desencadenan el potencial de patetismo contenido por las barreras del control social y porque entregan huellas, conocimientos fragmentarios que permiten descifrar, aunque sea imaginariamente, el enigma del mundo. Al respecto, dos tendencias parecen caracterizar la manera en que las ficciones hablan y expresan la incertidumbre del orden. En el primer caso encontramos textos que buscaron "poner freno" a la cadena de acontecimientos una vez desatada la tragedia, textos que explican o intentan construir un sentido a lo ocurrido, haciendo transitar la historia por el derrotero lineal de las certezas aunque, como ocurre con La guaracha del macho Camacho, solo sirva para desembocar ambiguamente en el pozo ciego de la culpa. En el segundo caso encontramos textos que, enfrentados a la tragedia, eligen la aceleración a riesgo de intensificar los atropellos, las colisiones y la desintegración. En estos casos los accidentes no finalizan ni concluyen nada, al contrario, funcionan como enigmáticos puntos de partida, explosiones o colisiones originales que recuerdan al big-bang astronómico: ¿Encontraría a la maga? ¿Quién conduce el Impala? ¿Qué hay detrás de la ventana? Posiciones formales que se proyectan retórica e ideológicamente hacia la experiencia de lectura, proponiendo sus inestables versiones del mundo. En este último sentido, construida como un rompecabezas intencionalmente defectuoso, Los detectives salvajes nos parece una muestra ejemplar de ficción que contiene y sufre accidentes como gesto estético a la par que político, en la medida en que conjura la posibilidad de una lectura clara y definitiva con sus accidentes de lectura, resistiendo la violencia que se ejerce desde la certeza sobre las posibilidades de lo imaginable.

Agreguemos, para finalizar, que los límites impuestos a nuestra investigación han dejado fuera de consideración otras "ficciones accidentadas" cuyo análisis podrá añadir nuevas facetas a la lectura propuesta. Las naos naufragando frente a las costas del Nuevo Mundo, grandes accidentes fundacionales de nuestra memoria colectiva; los accidentes fantásticos de Dabove, Arreola y Onetti, irónicos e impenetrables, o los 
falsos accidentes, como en Luna caliente de Mempo Giardinelli, que recrean la escena del complot y su forma secreta de orden, son textos que marcan algunos posibles itinerarios de lectura para futuras investigaciones.

\author{
Universidad de Concepción* \\ Facultad de Humanidades y Arte \\ Barrio Universitario s/n Concepción (CHILE) \\ eduardoaguayo@udec.cl
}

\title{
OBRAS CITADAS
}

Aguayo, Eduardo. "Octavio Paz y el accidente como imagen de mundo", Alpha 33 (2011):43-53.

Antonucci, Fausta. Juego, Rito y pasaje en "La autopista del sur", en Actas del Coloquio Internacional "Lo lúdico y lo fantástico en la obra de Cortázar". Madrid: Editorial Fundamentos, 1985.

Baudrillard, Jean. La société de consommation. Ses mythes, ses structures. Alcira Bixio (Trad.). Madrid: Siglo XXI, 2009.

------ L'échange symbolique et la mort. Trad. Iain Hamilton Grant. London: SAGE, 1993.

Belletto, Steven. No Accident, Comrade: Chance and Design in Cold War American Narratives. NY: Oxford University Press, 2012.

Beristain, Helena. Diccionario de retórica y poética. México: Editorial Porrúa, 1995.

Bolaño, Roberto. Los detectives salvajes. Barcelona: Editorial Anagrama, 1998.

------ Entre paréntesis. Barcelona: Editorial Anagrama, 2004.

Cortázar, Julio. Todos los fuegos el fuego. México, D.F.: Fondo de Cultura Económica, 2005.

------ Rayuela. Madrid: ALLCA XX.

------ Obra Crítica. Volumen 3. Madrid: Alfaguara, 1994.

Daly, Nicholas. Literature, technology and modernity, 1860-2000. Cambridge: Cambridge University Press, 2004.

De la Fuente, José. "La literatura del tapón: la narrativa de Emilio Díaz Valcárcel", Revista de Estudios Hispánicos 1 (2006):39-54.

De Mora, Carmen. Teoría y práctica del cuento en los relatos de Cortázar. Sevilla: Escuela de estudios hispanoamericanos de Sevilla, 1982.

Díaz Valcárcel, Emilio. El hombre que trabajó el lunes.Puerto Rico: Editorial Cultural, 1966.

Fernández, Macedonio. Museo de la Novela de la Eterna. Caracas, Venezuela: Biblioteca Ayacucho, 1982.

Ferré, Rosario. Papeles de pandora. México, D.F.: Joaquín Mortiz, 1987.

Filler, Malva. Los mundos de Julio Cortázar. New York. Las Américas Publishing Company, 1970. 
Fuentes, Carlos. "Sobre la nueva novela hispanoamericana", En Sosnowski, Saúl (Ed.) Lectura crítica de la literatura americana. Vol.4. Actualidades Fundacionales. Caracas: Biblioteca Ayacucho (1997):163-192.

Goodboy, Axel. Nature, Technology and Cultural Change in Twentieth-Century German Literature. The Challenge of Ecocriticism. New York, NY: Palgrave Macmillan, 2007.

Herralde, Jorge. Para Roberto Bolaño. Santiago: Catalonia, 2005.

López-Baralt, Mercedes. Literatura Puertorriqueña del siglo XX. Antología. San Juan: Editorial de la Universidad de Puerto Rico, 2004.

Matas, Julio. "El contexto moral en algunos cuentos de Julio Cortázar", Revista Iberoamericana Vol. XXXIX, Núm. 84-85 (1973):593-609.

Morales, Leonidas. "Roberto Bolaño: Las lágrimas son el lugar de la esperanza", Atenea 497 (2008):51-77.

Ortega, Julio. "El polisistema narrativo de Diamela Eltit". En Carreño, Ruby (Ed.) Diamela Eltit: redes locales, redes globales. Madrid: Iberoamericana (2009):49-60.

Paley de Francescato, Martha. "El viaje: función, estructura y mito en los cuentos de Julio Cortázar", En Lagmanovich, David (Ed.) Estudios sobre los cuentos de Julio Cortázar. España: Ediciones Hispam (1975):125-138.

Paz, Octavio. Conjunciones y disyunciones. Barcelona: Seix-Barral, 1991.

Pedreira, Antonio. Afirmación puertorriqueña, En López-Baralt, Mercedes (Comp.). Literatura puertorriqueña del siglo XX: antología. Puerto Rico: Editorial de la Universidad de Puerto Rico (2004):37-49.

------ Insularismos: ensayos de interpretación puertorriqueña. Madrid: Editorial Tipografía Artística, 1934.

Picon, Evelyn. Cortázar por Cortázar. Xalapa: Universidad Veracruzana, 1978.

Piglia, Ricardo. Crítica y ficción. Barcelona: Editorial Anagrama, 2001.

------"Prólogo". En Piglia, Ricardo (Ed.) Diccionario de la novela de Macedonio Fernández. Buenos Aires: Fondo de Cultura Económica de Argentina (2000): 7-9

Puskar, Jason. Accident Society: Fiction, Collectivity, and the Production of Chance. Stanford, CA: Stanford University Press, 2012.

Rein, Mercedes. Julio Cortázar: el escritor y sus máscaras. Montevideo: Diaco, 1967.

Rodríguez, Mario y José Rodríguez. "El delirio que viene de las ninfas en la novela latinoamericana. 'Nada más que ser feliz", Revista Chilena de Literatura 73 (2008):189-215.

Román, Raúl. "La guaracha del Macho Camacho: Texto de ruptura", Anales de Literatura Hispanoamericana 10 (1981):241-262.

Sábato, Ernesto. Hombres y engranajes. Buenos Aires: Seix Barral. 2006. 
Sánchez, Luis Rafael. "Cinco problemas al escritor puertorriqueño", En Sosnowski, Saúl (Ed.) Lectura crítica de la literatura americana. Vol.4. Actualidades fundacionales. Caracas: Biblioteca Ayacucho (1997):619-624.

------ La guaracha del Macho Camacho. Buenos Aires: Ediciones de la Flor. 1994.

Solotorevsky, Myrna. "Inestabilidad patemática en La guaracha del Macho Camacho', de Luis Rafael Sánchez, y 'Hagiografía de Narcisa la Bella', de Mireya Robles”, en Hispamérica 91 (2002):41-54.

Spiller, Rolland. "Roberto Bolaño: fracasar con éxito o navigare necessum est". En Yvette Sánchez, Roland y Spiller, Rolland (Comp.) Poéticas del fracaso, Tübingen: BoD (2009):143-174.

Varanini, Francisco. Viaje literario por América Latina. Barcelona: Quaderns Crema, 2000.

Vaquero de Ramírez, María. "Interpretación de un código lingüistico: La guaracha del Macho Camacho". En Revista de Estudios Hispánicos 5 (1978):27-69.

Virilio, Paul. L'accident originel. Trad. Irene Agoff. Buenos Aires: Amorrortu, 2005.

------ Cybermonde: La politique du pire? Trad. Cristóbal Santa Cruz. Santiago de Chile: Dolmen Ediciones. 1997.

Zambrano, María. Persona y Democracia: La Historia Sacrificial. Madrid: Siruela. 1996. 